\title{
ДИЗАЙН И МОДЕЛИРОВАНИЕ НАНОРАЗМЕРНЫХ АГРЕГАТОВ ДЛЯ САМОДОСТАВКИ НИЗКОМОЛЕКУЛЯРНЫХ ЛЕКАРСТВЕННЫХ СОЕДИНЕНИЙ
}

\author{
А.С. Бабушкин, Д.А. Горшенин \\ Кафедра органической химии, ВолгГТУ, \\ 400005, Россия, г. Волгоград, проспект им. В.И. Ленина, 28.
}

DOI: 10.19163/MedChemRussia2021-2021-312

E-mail: asbabyshkin@gmail.com

Наноагрегаты малых молекул (НМM) вызывают растущий интерес к применению в биомедицинской сфере для адресной доставки лекарственных веществ, диагностики, терапии и др. [1]. Мы считаем, что есть веские основания уделить особое внимание изучению возможности формирования наноагрегатов из низкомолекулярных лекарственных соединений, поскольку такие НММ могут обладать дополнительными преимуществами в биомедицинских приложениях [1]. Так, они могут быть использованы для самодоставки лекарственных соединений, которая перспективна тем, что позволяет отказаться от применения специально предназначенных носителей [2]. Последние, зачастую, обладают недостатками, включающими токсичные свойства или малую изученность с точки зрения безопасности, низкую синтетическую доступность и др. С другой стороны, самодоставка позволяет не только сохранить, но и усилить важные преимущества систем доставки лекарственных соединений в целом: возможность снижения общей токсичности, увеличения терапевтического эффекта и биодоступности [2]. В тоже время, при всех имеющихся перспективах, рациональная разработка НММ представляет собой серьезный вызов для исследователей, поскольку до сих пор механизмы их образования изучены не в полной мере [3]. Тем не менее, за последние годы в перечисленных областях накоплен большой объем экспериментальных данных и достигнут заметный прогресс в теоретических результатах, которые привели к ряду успехов в рациональном дизайне НММ [2]. Исходя из вышеизложенного, нами на основе имеющихся литературных данных и с помощью известных методов вычислительной химии разрабатываются подходы к созданию и осуществляется молекулярное моделирование ряда супрамолекулярных наноагрегатов для самодоставки низкомолекулярных лекарственных соединений.

\section{Литература}

[1] J. Shi and B. Xu, Nano Today. 2015, 10, 615-630

[2] S.-Y. Qin, A.-Q. Zhang, S.-X. Cheng, L. Rong and X.-Z. Zhang, Biomaterials. 2017, 112, 234-247

[3] H.J. Schneider, New J. Chem.. 2019, 43, 15498-15512 